\title{
INVERTENDO A LÓGICA: CRIANÇAS ENSINANDO CIRCO PARA ADULTOS - TODOS APRENDENDO
}

\section{REVERSING LOGIC: CHILDREN TEACHING CIRCUS FOR ADULTS- EVERYONE LEARNING}

\section{INVIRTIENDO LA LÓGICA: NIÑOS ENSEÑANDO CIRCO PARA ADULTOS - TODOS APRENDIENDO}

\author{
Caroline Capellato Melo ${ }^{1}$ \\ Gilson Santos Rodrigues ${ }^{2}$ \\ Leonora Tanasovici Cardani ${ }^{3}$ \\ Mônica Lua Barreto ${ }^{4}$ \\ Marco Antonio Coelho Bortoleto ${ }^{5}$
}

1 Mestre em Educação Física pela Universidade Estadual de Campinas. Grupo de Pesquisa em Circo (CIRCUS/ FEF- UNICAMP). ORCID: https://orcid. org/0000-0002-2584-5355. E-mail: carolcmelo_9@hotmail.com

2 Estudante de Doutorado - Faculdade de Educação Física/Unicamp. Departamento de Educação Física e Sociedade e Grupo de Pesquisa em Circo - CIRCUS. Mestre em Educação Física pela Universidade Estadual de Campinas. ORCID: https://orcid.org/0000-0002-1472-2480. E-mail: g106009@dac.unicamp.br

3 Mestra em Educação Física-Faculdade de Educação Física/ Unicamp. Grupo de Pesquisa em Circo (CIRCUS/ FEF- UNICAMP). ORCID: http://orcid. org/0000-0002-1530-8476. E-mail: norataca@hotmail.com

4 Estudante de Doutorado - Faculdade de Educação Física / Unicamp. Grupo de Pesquisa em Circo (CIRCUS/ FEF- UNICAMP). Mestra em Performances Culturais pela Universidade Federal de Goiás (UFG). ORCID: https://orcid. org/0000-0003-3314-9138. E-mail: m212134@dac.unicamp.br 
5 Post-doutorado. Professor Doutor da Faculdade de Educação Física/ Universidade Estadual de Campinas. Grupo de Pesquisa em Circo (CIRCUS). Departamento de Educação Física e Sociedade. UNICAMP. ORCID: https:// orcid.org/0000-0003-4455-6732. E-mail: bortoleto@fef.unicamp.br

Capellato Melo, C.; Santos Rodrigues, G.; Tanasovici Cardani, L.; Lua Barreto, M. \& Coelho Bortoleto, M. A. Invertendo a lógica: crianças ensinando circo para adultos - todos aprendendo. Educación Física y Deporte, 38(2), 357-381. Jul.-Dic. http://doi. org/10.17533/udea.efyd.v38n2a07 


\section{RESUMO}

O presente estudo analisa uma experiência pedagógica desenvolvida em um projeto de extensão universitária intitulado "Atividades circenses para crianças" e que oferece, semestralmente, uma aula aberta na qual as crianças se tornam "professoras" de seus familiares. Através dos planos de aula e dos depoimentos dos adultos participantes, temos notado que a aula aberta é um espaço de socialização que permite aos adultos experienciar e reconhecer os desafios enfrentados pelas crianças, além de ser um momento para resgatar suas infâncias. Para as crianças, ela reforça o engajamento nas atividades que podem ajudar no processo de ensino. Com isso, entendemos que a atividade se mostra fulcral para o aprendizado das crianças e para que os responsáveis se aproximem ao processo que elas têm vivido no que tange à prática do circo.

PALAVRAS-CHAVE: Pedagogia; Extensão Universitária; Aula aberta; Participação familiar; Atividades circenses.

\section{ABSTRACT}

This study analyzes a pedagogical experience developed in a university extension project called "Actividades circenses para niños", offering every semester an open class in which children become "teachers" of their families. Through the lesson plans and the testimonies of the participating adults, we have noted that this open class is a space of socialization allowing adults to experience and to recognize the challenges faced by children, beyond being a moment of rescue of his childhood. For children, this class reinforces the engagement in the activities that can help in the teaching process. For this reason, we understand that this activity is essential for children's learning and so that responsible adults can approach the process experienced with children in relation to the practice of the circus.

KEYWORDS: Pedagogy; university extension open class; family participation; circus activities.

\section{RESUMEN}

En este estudio se analiza una experiencia pedagógica desarrollada en un proyecto de extensión universitaria denominado "Actividades circenses para niños" y que ofrece, cada semestre, una clase abierta en la que los niños se convierten en "profesores" de sus familias. A través de los planes de clase, y de los testimonios de los adultos participantes, hemos notado que esta clase abierta es un espacio de socialización que permite a los adultos experimentar y reconocer los retos a los que se enfrentan los niños, más allá de ser un momento para rescatar su niñez. Para los niños, ella intensifi- 
ca el compromiso en las actividades que pueden ayudar en el proceso de enseñanza. Por ello, comprendemos que la actividad se demuestra esencial para el aprendizaje de los niños y para que los responsables se acerquen al proceso que han vivido ellos con relación a la práctica del circo.

PALABRAS-CLAVE: Pedagogía, Extensión Universitaria, Clase abierta, Participación de la familia, Actividades circenses. 


\section{INTRODUÇÃO}

Segundo Rocha (2012), a noção de "circo-escola" representa um espaço simbólico, composto por agentes, objetos e saberes aos quais são ensinados valores, comportamentos e técnicas que, em última instância, visam distintos objetos formativos. Ademais, adiciona Santos Rodrigues (2018), a ideia de "circo-escola" colige diferentes manifestações circenses: Circo itinerante de lona como escola, escolas de Circo, Circo social (como escola não-formal) e Circo na/da escola (no ensino escolar básico, médio e superior).

A noção de "circo-escola" apresentada por Rocha (2012), permite uma compreensão ampliada dos espaços e das práticas que contribuem para a manutenção do circo como um fenômeno sociocultural. Parece-nos que as atividades circenses desenvolvidas no âmbito da extensão universitária, conforme discutem Bortoleto \& Celante (2011) e Miranda \& Ayoub (2017), poderiam ser incluídas nessa noção, uma vez que reforçam o ensino do circo para um amplo contingente de pessoas, com ou sem o interesse artístico-profissionalizante.

Por outro lado, partindo de uma premissa em que as atividades de ensino, pesquisa e extensão universitária estão intrinsecamente interconectadas, Freire (2015) e Tonso (2012) defendem uma visão de Universidade pública capaz de articular, de modo indissociável, as atividades nesses três eixos estruturantes. Portanto, a prática educativa/pedagógica do circo, que passa a figurar em muitas das universidades brasileiras (Bortoleto et al., 2017), precisa mostrar essa articulação entre os saberes produzidos na universidade e o envolvimento da comunidade com tais conhecimentos.

Efetivamente, a implementação de projetos de circo na Universidade, ainda que ocorra por entre as gretas dos currículos, como discutem Bortoleto \& Silva (2017), já é uma realidade em diversas instituições de ensino superior (Tucunduva, 2015). 
Com efeito, é relevante o número de atividades de pesquisa com/sobre o circo em instituições brasileiras, como indicam Silva (1996), Rocha (2010) e Ontañón et al. (2012). No entanto, apesar desse aumento nas atividades de pesquisa com a temática circense, Ribeiro et al (2017) mostram que o Circo ainda permanece à margem dos programas de pesquisa no Brasil, em especial na área da Educação Física.

Nesse contexto, notamos, igualmente, o aumento considerável da quantidade de relatos de atividades de ensino com a temática circense no ensino superior em Educação Física (Miranda \& Bortoleto, 2018). Associada às atividades anteriores, parece-nos que a extensão universitária, como apontam Ontañón et al. (2016), De Gáspari \& Schwartz (2007) e Caramês (2014), estabelece um importante espaço de diálogo da Universidade com a comunidade, beneficiando, de maneira mais geral, o circo. Logo, entendemos que a Universidade vem ampliando o espaço de manifestação da linguagem circense (Duprat, 2014).

De fato, Ontañón et al. (2016) destacam que essas atividades desenvolvidas no contexto da extensão universitária, representam um espaço de formação por excelência em que, na maior parte das vezes, os estudantes de graduação podem assumir uma experiência docente segura e articulada com a pesquisa. Na contramão da inércia docente denunciada por Bourdieu (2004), para quem o ato de ensinar tende, na maioria das vezes, à transmissão codificada, à rotinização do saber e à falta de vínculo com as atividades de pesquisa, a extensão universitária representa, em nosso ponto de vista, uma oportunidade de articular ensino e pesquisa para a concreção de inovações pedagógicas (Faria et al., 2010; Fino, 2016; Almeida, 2017) ou, como define Santos (2018), de ter "experiências docentes compartilhadas". Além disso, esse espaço permite maior interação com a sociedade, de maneira que a comunidade se beneficie dos saberes gerais de modo mais rápido e direto (Bortoleto et al., 2016). 
Dentre as inovações e renovações pedagógicas que mais debates geraram nos últimos anos, consideramos que as concepções de aulas abertas, direta ou indiretamente inspiradas em Hildebrandt \& Laging (1986), podem representar uma experiência significativa no que tange ao ensino, tanto para estudantes quanto para professores. Do ponto de vista conceitual, Almeida et al. (2011) entendem que as aulas abertas são propostas de ensino caracterizadas pela participação dos estudantes nas decisões referentes aos objetivos, à seleção de saberes e de conhecimento e às metodologias de ensino e de avaliação do processo pedagógico. Ademais, Hirai \& Cardoso (2006) complementam que as concepções de ensino nessa perspectiva são orientadas por quatro eixos basilares: o estudante, o processo pedagógico, a problematização dos saberes e dos conhecimentos e a comunicação dos estudantes entre si e com o professor. Em síntese, a inovação pedagógica engendrada pela concepção de aulas abertas refere-se ao aumento da participação, da motivação, da autonomia e da comunicação dos estudantes nas aulas de Educação Física, como argumentam Matias et al. (2018).

Isto posto, o presente estudo se fundamenta em uma experiência construída em um projeto de extensão universitária que articula as atividades de ensino e de pesquisa, visando a produção de inovações pedagógicas que encorajem diferentes iniciativas de ensino do circo. Assim, o objetivo deste trabalho foi analisar uma proposta de aulas abertas aos familiares das crianças que participaram do projeto em questão, intitulado "Atividades circenses para crianças". Neste estudo, adotamos a noção alargada de família de Afonso (2002). Logo, subjaz o entendimento que sob o signo "família" está atrelado tanto pessoas com laços de consanguinidade (pais, mães, avós, irmãos etc.), quanto de não consanguinidade (padrastos, madrastas, pais/mães adotivos etc.).

O que justifica a sobredita aula aberta são as seguintes demandas: em primeiro lugar, houve a necessidade de o projeto 
integrar as famílias à proposta pedagógica, haja vista o indicativo de que os familiares desconheciam o papel da extensão universitária e dispunham de representações rasas da arte circense. Por certo, o Circo não fez parte de seus saberes escolarizados, sendo, então, mediado apenas pelo imaginário do senso comum. Por conseguinte, o projeto buscou dirimir a distância entre o conhecimento ensinado às crianças e os saberes transmitidos pelas famílias. Por outro lado, havia a intenção de fazer com que as crianças criassem diferentes mecanismos de aprendizagem e que esses mecanismos se tornassem conhecidos pelos adultos responsáveis por elas. Portanto, a aula aberta é composta por essas duas demandas, isto é, dialoga com a família e fomenta o desenvolvimento das crianças durante as aulas e fora delas.

\section{Itinerário metodológico}

Do ponto de vista teórico-metodológico, este trabalho se caracteriza como pesquisa de natureza qualitativa numa abordagem hermenêutica ou interpretativa (Flick et al., 2004) e, quanto ao delineamento da pesquisa, configura-se como um estudo de caso (Yin, 2001), no qual os planos pedagógicos e os depoimentos dos familiares foram usados como fontes de dados (Denzin \& Lincoln, 2005). Desde o princípio foram realizados registros fotográficos, utilizados como fonte de informações complementares. No entanto, por razões éticas, as imagens não foram utilizadas no artigo, visando preservar a identidade dos participantes. Desse modo, os planos pedagógicos e os depoimentos dos familiares (escritos de próprio punho) compuseram o corpus documental que foi lido.

Quando ao processo analítico, de Análise de Conteúdo (Krippendorff, 2004), decorreu a partir da leitura do corpus documental foram destacados os temas significantes (unidade de análise) que a posteriori foram agrupados em pontos comuns e incomuns (divergentes). Destes agrupamentos temáticos elaboramos categorias e subcategorias que foram interpretados em 
diálogos com a literatura (vide os exemplos dispostos na figura 1 mais à frente). Os resultados são apresentados em formato de narrativa e atende ao objetivo central do estudo.

O critério de seleção do projeto foi a regularidade da sua oferta de aulas de Circo, continuamente desde 2006, bem como por articular o tripé da universidade pública: pesquisa, ensino e ação ou extensão comunitária). Todos os planos pedagógicos foram obtidos na íntegra com os responsáveis pelo projeto e para os depoentes não houve um critério de seleção prévio. Sendo assim, todas as crianças regularmente matriculadas no projeto participaram da pesquisa. Do mesmo modo, todos os familiares que se disponibilizaram a relatar sua experiência com a aula aberta tiveram o depoimento acrescido ao corpus documental. Cabe indicar que todos os depoentes assinaram o Termo de Consentimento Livre e Esclarecido como condição prévia para participar do estudo e a pesquisa foi previamente aprovada pelo Comitê de Ética em Pesquisa sob o parecer número 786.757.

Os planos pedagógicos correspondem ao período de 20142019. Em relação aos depoimentos dos responsáveis, os mesmos começaram a ser produzidos a partir de 2016 (Tabela 1), contabilizando 81 depoimentos escritos, distribuídos da seguinte maneira:

Tabela 1. Fonte principal de dados - depoimentos

\begin{tabular}{cc}
\hline \multicolumn{2}{c}{ Quantidade de depoimentos por turma } \\
\hline Turma & Número de depoimentos \\
\hline $2^{\circ} \mathrm{sem} . / 2016$ & 15 \\
$1^{\circ} \mathrm{sem} . / 2017$ & 21 \\
$2^{\circ} \mathrm{sem} . / 2017$ & 13 \\
$1^{\circ} \mathrm{sem} . / 2018$ & 12 \\
$2^{\circ} \mathrm{sem} . / 2018$ & 8 \\
$1^{\circ} \mathrm{sem} . / 2019$ & 12 \\
\hline
\end{tabular}

Fonte: autoria própria 
Em termos procedimentais, os planos pedagógicos são produzidos coletivamente entre os monitores e o coordenador do projeto (Ontañón et al., 2016; Santos et al., 2016). A produção dos depoimentos seguiu um processo sistemático: no terço final da aula aberta, os responsáveis eram convidados a elaborar um depoimento, por aproximadamente 15 minutos. A orientação dada aos depoentes foi a de relatar sua percepção sobre a proposição e experiência em aula, dispondo de total liberdade para expressar suas opiniões e impressões acerca do trabalho realizado. Não era preciso identificar o relato, mantendo, dessa forma, o anonimato.

Ao mesmo tempo, as crianças se reuniam em uma roda para conversar com os monitores sobre a aula, de modo similar ao descrito por Chioda (2018). Na roda, os monitores problematizavam as dificuldades encontradas pelas crianças, no entanto esses dados não foram considerados na análise para esse momento.

A análise dos dados, se realizou por meio de uma metodologia colaborativa (Ibiapina, 2016). De início, foram usados planos pedagógicos para descrever o processo de constituição das aulas abertas ao longo do projeto. Esse processo foi feito coletivamente pelos autores que colocaram o corpus documental no "centro de uma roda de conversa" e, a partir de seus pontos de vista, elencaram significados que, por fim, foram socializados com os demais autores.

Vale destacar, como alega Silva (2009), que cada investigador dispõe de uma perspectiva do fenômeno, mas para desvelar o não aparente, a face oculta, foi preciso discutir os significados apontados por cada pesquisador. Na discussão, os significados foram organizados em pontos convergentes e divergentes e, a partir da síntese dessa discussão, foram produzidos os resultados do estudo.

No processo de análise dos depoimentos, a primeira medida foi organiza-los por semestre, em seguida, cada pesquisador 
fez sua leitura individual a fim de compreender o fenômeno relatado. Logo após, levantamos significados, os agrupamos em sínteses, compartilhamos os resultados e discutimos de modo coletivo. O produto dessas discussões foi documentado e, por conseguinte, engendrou outros resultados, conforme Desgagné (2007). Por fim, os resultados consistem, resumidamente, numa análise da constituição histórica das aulas abertas dentro do projeto em questão ("de um espaço de socialização à inversão da lógica docente") e na análise das representações das aulas abertas para os familiares em relação a si mesmos e às crianças ("representações da aula aberta nos depoimentos dos familiares").

\section{Caracterização do projeto de extensão \\ Atividades circenses para crianças}

O projeto de extensão "Atividades circenses para crianças" está em atividade em uma Faculdade de Educação Física da Universidade Estadual de Campinas desde 2006. Dando suporte às atividades de ensino e extensão, destaca-se a participação dos pesquisadores do Grupo de Estudo e Pesquisa das Artes Circenses (CIRCUS) (Bortoleto et al., 2016). As ações do projeto visam, prioritariamente, a formação inicial dos monitores e, para isso, contam com o suporte do grupo de pesquisa (Bortoleto et al., 2016). De modo geral, as atividades são desenvolvidas com a participação direta de quatro a cinco monitores, porém a quantidade pode variar conforme os semestres. Ontañón et al., (2016) e Santos et al., (2016), citam que esse projeto é um campo fértil para a investigação, pois a extensão é propícia às inovações pedagógicas.

Quanto à participação, o projeto é oferecido semestralmente, exigindo uma matrícula para cada período. Não há nenhum pré-requisito para a inscrição das crianças e a faixa etária de participação delas varia entre 6 e 12 anos de idade. Em cada semestre são oferecidas 20 vagas, com participação da comunidade interna (maioria) e da comunidade externa à Universidade, 
sendo que muitas crianças permanecem por mais de um semestre. Em cada semestre letivo (4 meses efetivos) são realizadas 15 aulas, de 1h30min cada uma, uma vez por semana.

Em relação à proposta pedagógica, o objetivo é proporcionar uma experiência inicial com o circo. Para tanto, as aulas são fundamentadas na proposta pedagógica desenvolvida pelo grupo CIRCUS/FEF-Unicamp em mais de uma década de trabalho (Bortoleto et al., 2016). De modo mais específico, a aula aberta simboliza um espaço de aproximação entre as famílias, bem como um meio de comunicação com os adultos responsáveis pelas crianças (Cardani et al., 2017).

\section{Quando pais se tornam alunos de seus filhos: de um espaço de socialização à inversão da lógica docente}

A análise dos planos das aulas revelou que o formato delas, bem como o processo de preparação e alguns dos saberes abordados, foram sendo modificados semestralmente, o que evidenciou um constante dinamismo nessa atividade. Nesse sentido, destacam-se as mudanças ocorridas entre os anos de 2014 e 2019, que conduziram a aula aberta ao modelo centrado no estudante. Em vista disso, notamos nos últimos dois anos uma participação mais ativa das crianças, excelente receptividade das famílias e, de modo geral, melhoras na comunicação do projeto com sua comunidade.

O primeiro registro é datado do primeiro semestre de 2014. A análise dos documentos mostrou que a aula aberta representava um espaço de socialização das famílias e das crianças. Naquele momento, a aula estava centrada no processo de formação dos monitores que selecionavam os saberes e conhecimentos circenses, elaboravam as atividades, ministravam e avaliavam as aulas. Essa estrutura didático-pedagógica foi mantida ao longo do semestre seguinte. Desse modo, o objetivo era proporcionar um momento de convivência da família com as crianças. 
No primeiro semestre de 2015 foi mantida a estrutura anterior centrada nos monitores. Todavia, a análise das fotografias evidenciou uma mudança de atitude das crianças que, cada vez mais, assumia o papel docente junto aos familiares na execução das tarefas. Foi assim que os monitores, junto ao coordenador, engendraram um espaço maior de decisão e participação dos alunos nas aulas . Em vista disso, no segundo semestre de 2015, foi proposta uma atividade de criação e apresentação de número circense, em que as crianças se apresentavam junto aos familiares. Os indícios apontam que o resultado da apresentação foi bastante positivo no que concerne à expressão/comunicação das crianças, conforme apontam Alonso \& Barlocco (2013) e Santos (2018). Apesar disso, a autonomia e participação delas na estruturação da aula aberta ficou aquém das expectativas.

Em decorrência disso, no primeiro semestre de 2016 foi registrado que as crianças ficaram responsáveis pela seleção coletiva e pela condução da atividade de preparação corporal ou de aquecimento. A iniciativa foi bem-sucedida e no segundo semestre de 2016 a aula passou, de modo efetivo, a ser orientada e conduzida pelas crianças. De fato, as crianças passaram a ser responsáveis pela seleção e decisão dos temas e das atividades e pela condução, como um todo, da aula aberta. Foi também nesse semestre que os pais começaram a produzir os depoimentos que analisaríamos mais tarde.

Como consequência, a assunção das crianças pela seleção, organização e condução da aula, denominada de inversão da lógica docente (Cardani et al., 2017), foi mantida para o ano de 2017. Percebemos que as crianças começaram a ensinar, ainda que de maneira tímida, outros adultos, além dos parentes. Porém, o plano pedagógico sugere que apesar de a iniciativa nutrir a autonomia, tomada de decisão/co-decisão e motivação das crianças, para os adultos houve uma queda na qualidade da experiência circense, ora pela timidez de certos estudantes, ora pelo caráter de "improviso" em que a aula estava baseada. De 
fato, nesse momento do projeto o processo de organização e condução ocorria em uma única sessão. Todavia, no segundo semestre do ano de 2017 houve a inclusão, no plano pedagógico, de uma aula preparatória, aula esta que se manteve durante os dois semestres de 2018 e no primeiro de 2019, permitindo às crianças discutem os temas e atividades, dividem funções e responsabilidades e ensaiarem a dinâmica da aula. Em suma, a inclusão da aula preparatória, além de potencializar a participação ativa das crianças, viabilizou aos monitores ensinar às crianças noções básicas de pedagogia e didática, conforme sugerem Hildebrandt \& Laging (1986).

A aula preparatória tornou-se central para o processo de organização da aula aberta: seleção e co-decisão de atividades, divisão de tarefas, ensaio do discurso a ser pronunciado e ensaio da preparação do espaço da aula. Ademais, os monitores conseguiram melhor orientar as crianças quanto aos procedimentos de segurança e de ajudas (manuais e instrumentais) na realização das tarefas. Com a estabilidade desse modelo de aula por quatro semestres, avultam-se certos significados no que compreende a conduta, o comportamento e o discurso dos participantes. Em 2019 ocorreram algumas mudanças, os alunos continuaram com a tarefa de explicar os exercícios, mas agora em um grande grupo, assim eles puderam viver não somente a experiência de explicar, como também de vivenciar a própria aula com os seus familiares.

\section{Meu filho, meu professor: representações da aula aberta nos depoimentos dos familiares}

A análise dos depoimentos permitiu ainda identificar muitas representações das aulas abertas na ótica dos familiares das crianças. Em vista da orientação que foi dada aos depoentes, notou-se que os sujeitos escreveram sobre vários assuntos. Por esse motivo, a análise resultou em temáticas diferentes que, após serem debatidas, foram alocadas em quatro núcleos te- 
máticos: percepções relacionadas ao "projeto", à "proposta de aula", "em relação a si mesmo" e "relativo ao filho(a)" (Figura 1). Porém, devido aos limites deste estudo somente dois dos quatro núcleos serão tratados nesta oportunidade.

A figura 1 mostra as unidades temáticas resultantes da análise dos depoimentos.

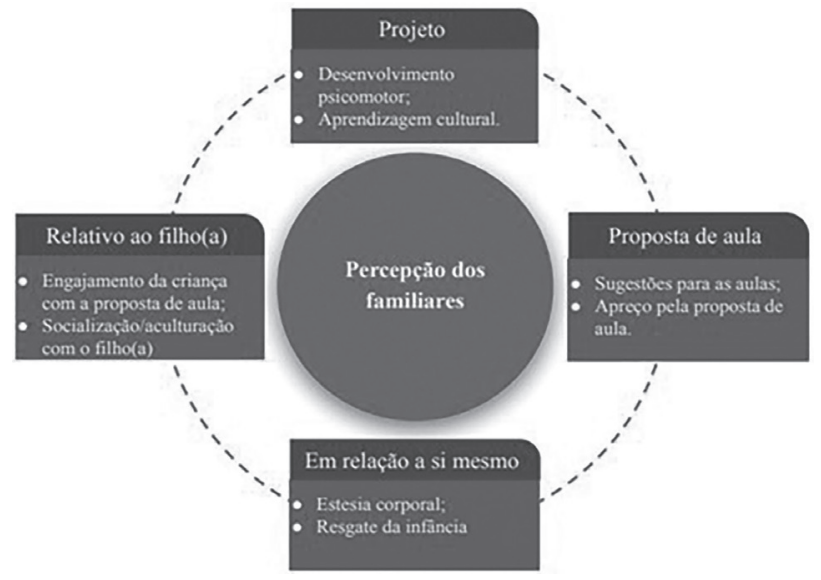

Figura 1. Representações da aula aberta nos depoimentos dos familiares.

Fonte: autoria própria.

Na unidade temática referente à percepção dos familiares em relação a si mesmo, destacam-se os subtemas: estesia ${ }^{1}$ e resgate da infância. No que concerne à estesia, como entendem Nóbrega (2008) e Andrieu (2016), são representações avultadas

1 No sentido dado por Nóbrega (2008). Como exemplo, pode-se pensar no filme Ratatouille, produzido pela Disney em 2007, em específico na cena em que a personagem Anton Ego ao provar a comida é imediatamente arrebatada por uma sensação que lhe conduz imediatamente a um momento da infância, ou seja, uma vivência ambígua de passado e presente, de sensação e história vivida, em suma, uma experiência única e singular daquele que a vive. 
pela experiência da aula aberta com atividades circenses, que resultam da sensibilidade, afetividade e historicidade vivida de modo corporal. Logo, depreende-se que a estesia é uma resultante dessa experiência do adulto com o circo, como sugere este relato de um depoente:

Para mim foi muito interessante subir na bola chinesa, mas senti maior dificuldade na tábua sobre o rolo [rola-rola] (Depoimento 13, 1s-2016).

Outro depoimento cita o medo atrelado à própria aula aberta.

Inicialmente, ao receber o convite de participar desta aula, pensei em recusar, talvez por medo ou outro sentimento relacionado, como limitação ou mesmo da nossa menina ficar desapontada [...] No entanto foi muito legal e interessante [...] "brincar" com as atividades, $[. .$.$] ver a desenvoltura das crianças e delas "atuarem"$ como professores (Depoimento 1, 1s-2018).

Podemos notar por esses relatos que a aula aberta proporcionou um espaço de experimentação aos familiares, o que permite-lhes lançar um outro olhar para as atividades que seus filhos realizam. Ainda, sentimentos como medo e ansiedade foram aludidos, como no seguinte relato:

Eu fiquei com medo na cama elástica, na bola [chinesa]; não tive força para subir no tecido, nem coordenação suficiente para manejar as bolinhas (Depoimento 12,1s-2017).

Por meio da experiência estésica relatada nos depoimentos durante a aula aberta, os familiares puderam experimentar os sentimentos que os filhos vivenciam em aula. Em vista disso, percebemos a relevância dessa prática da realização das atividades pelo adulto, sobretudo por fomentar a empatia para com a criança (Carvalho, 2004).

Há, ainda, outro relato cujo discurso foi debatido, pois trouxe uma nova representação, a de que a aula aberta teria Ihe proporcionado um resgate à infância. Nota-se nos depoimentos 
uma nostalgia por esse momento situado no passado, como ilustra o seguinte relato:

Meu sentimento foi de resgate da minha própria infância (Depoimento 4, 1s-2016).

Não obstante ao fato de a infância ser uma invenção cultural (Ariès, 2006), na ótica dos depoentes ela está atrelada à brincadeira, não-seriedade, liberdade etc., como expresso no relato a seguir:

Ao nos tornarmos adultos às vezes esquecemos da alegria de brincar, de pular, de cair. Essa vivência proporcionou momentos de resgate da infância, vi adultos rirem de seus tombos, voarem como Peter Pan, escalarem sonhos, equilibrarem emoções, treinarem uma concentração descontraída relaxada. Vi crianças ensinarem como adultos, melhor que muitos adultos, com carinho, paciência e compreensão. Me dei conta que certas coisas que pareciam fáceis, coisas de criança, na verdade, são mais difíceis do que parecem, requerem treino, concentração, perseverança (Depoimento 19, 1s-2017).

Entrementes, a dualidade infância-adultidade é confrontada pelos próprios depoentes. Quando um adulto comenta:

Minha filha se sentiu muito importante e falava com propriedade sobre a atividade que ela ficou responsável (Depoimento 3, 1s-2017).

Sugere que determinada representação da infância não condiz com a realidade, pois as crianças também se mostraram responsáveis, atentas, engajadas com as atividades ditas sérias e rotineiras. Destarte, notamos que a experiência da aula aberta foi capaz de problematizar a dualidade infância-adultidade, atrelada a uma nostalgia da infância. Na unidade temática "relativo ao filho(a)" foi discutido o engajamento das crianças com a proposta da aula aberta. De fato, a inversão da lógica docente não passou despercebida: 
[a] ideia deles [as crianças] estarem à frente das atividades foi significante... Eles se sentiram importantes e com responsabilidades" (Depoimento 3, 1s-2017).

Esse relato reforça a perspectiva de Hildebrandt \& Laging (1986) para quem a participação ativa na preparação e condução da aula consiste em uma fonte de motivação para as crianças. Outros depoimentos indicam que na docência tutorada as crianças demonstraram estar preparadas para a tarefa.

Minha filha estava contando os dias para essa atividade. Se sentiu muito importante e falava com propriedade sobre a atividade que ela ficou responsável (Depoimento 3, 1s-2017).

Essa inversão de papéis foi uma experiência muito interessante. Ver as crianças tão compenetradas e seguras de si no desempenho de suas tarefas e os adultos tão inseguros, se deixando conduzir pelos filhos, representa uma quebra de paradigma (Depoimento 12, 2s-2017).

É de suma importância destacar que a assunção de um papel docente pelas crianças na aula aberta é fundamentada por uma intencionalidade pedagógica, como defendem Hildebrandt \& Laging (1986). Nesse sentido, os monitores não estão ausentes, ao invés, assumem um papel de mediação das situações, para que as crianças participem da proposta de docência tutorada com a temática circense. Logo, o papel dos monitores na aula aberta no modelo supracitado é o de incentivar os estudantes a vivenciar o papel docente resolvendo conflitos, dialogando com colegas, fazendo escolhas e elaborando ações a serem desenvolvidas de modo autônomo e criativo.

Por fim, havia depoimentos cujas representações destacavam a aula aberta como um lugar de socialização/aculturação com as crianças, como pode ser visto no seguinte relato:

Nós gostamos muito da aula pois é um momento de interação criança x pais" (Depoimento 5, 1s-2019). 
Nesse sentido, há que se destacar a relevância da compreensão da tríade pedagógica: professor-estudante-conhecimento (Geraldi, 2010). Os relatos apontam que os familiares, acostumados ao papel de professor, foram surpreendidos ao se tornarem alunos de seus filhos no ensino do conhecimento do circo.

Esta experiência me fez perceber como os papéis de professor e aprendiz funcionam, a atenção ao que o professor quer passar e como eles se sentem na responsabilidade de algo que possa acontecer com seu aprendiz.

É interessante estar na posição de aprendiz, pude notar o empenho em mostrar e garantir a segurança e colocar limites. Houve um momento que ao subir no tecido, devido à minha familiaridade, ousei ir mais alto e ouvi "É melhor você descer, mas calma, para não queimar a mão" e ficou por perto com os braços para cima gesticulando que estaria ali para me amparar, caso precisasse, mesmo tendo ideia da diferença entre nossas proporções (Depoimento 2, 2s-2017).

Podemos observar nessa experiência pedagógica que o circo se tornou um catalisador da inversão da lógica docente. $\mathrm{Na}$ medida em que o imaginário circense das crianças passou a ser permeado por experiências e informações sistematizadas pela pedagogia das atividades circenses, nota-se que elas passaram a dispor de saberes dos quais os familiares não tiveram acesso. Como consequência, as crianças passaram a dispor de uma autoridade da experiência com o circo, conforme afirma Benjamin $(2009,2012)$, que os habilitaram a ensinar seus familiares. Portanto, a aula aberta tornou-se o local propício às trocas de experiências entres filhos(as) e suas famílias, conforme alega Hildebrandt (2005).

Por fim, as fontes indicam que a aceitação da proposta de aula aberta pelos familiares foi positiva, tendo em vista que eles participaram ativamente das atividades como alunos de seus filhos. Não obstante ao receio de alguns adultos, como citado 
anteriormente, de modo geral, mostraram-se alegres, contentes e motivados em aprender circo com as crianças. Quanto aos infantes, indícios sugerem que se sentiram motivados e alegres com a proposta da aula aberta sob o modelo de inversão da lógica docente. Entende-se, portanto, que o ensinar representa uma fonte de motivação para as crianças, que atrelada à afetividade de ensinar sua família, converte esta aula em uma inovação pedagógica passível de adaptações para outros contextos também pedagógicos.

\section{CONSIDERAÇÕES}

O que representa para uma criança ensinar seu pai, mãe, avô, avó em um contexto de ensino institucionalizado? O que simboliza para um adulto ir à escola aprender uma arte secular tendo crianças, dentre elas seus filhos e filhas, como professoras? Foram tais questões que incitaram a proposta de aula aberta aos familiares no projeto de extensão universitária "Atividades circenses para crianças". Por certo, o impacto dessa experiência de inversão da lógica docente seria significativo para qualquer pessoa, seja criança ou adulto. Foi com base na falta de relatos que convergissem para essa tendência que nos encorajamos a investigar esta experiência pedagógica.

Ao retomar o objetivo deste estudo, percebemos que para cumpri-lo foi preciso seguir dois percursos. O primeiro foi relatar o processo de constituição histórica das aulas abertas. $\mathrm{O}$ estudo mostrou que elas começaram como um local de socialização das famílias, pois o foco estava orientado somente para a formação dos monitores. Porém, ao longo do tempo, visando diminuir a distância entre os saberes circenses ensinados no projeto e as representações de circo transmitidas pelas famílias e, também, para engendrar mecanismos de síntese do aprendizado dos estudantes, a aula aberta foi sofrendo mudanças até culminar no 
modelo de inversão da lógica docente ou docência tutorada. A pesquisa revelou que este modelo de aula centrado no estudante pode contribuir no desenvolvimento da autonomia, da tomada de decisão e co-decisão, no diálogo, na responsabilidade e na motivação das crianças.

Quanto ao segundo itinerário, o estudo indicou que para os adultos a aula representa um momento de estesia em que sentimentos de medo, ansiedade e alegria são experimentados corporalmente. Também indicou que a experiência confronta a dualidade infância-adultidade. Por outro lado, para as crianças, a aula em questão simboliza o momento de engajamento e responsabilidade, não somente pelo cumprimento das tarefas, mas também pela criação de um local em que eles ensinam o circo aprendido para seus familiares.

Assim, notamos que a relação da família com o processo educativo da criança tende a manter uma relação de poder favorável ao adulto, uma vez que o trabalho apresentado propõe essa mudança de papéis que implica em uma participação ativa da criança em todas as fases (planejamento, organização, execução e avaliação) dessa metodologia de aula, sem perder de vista a importância dessa aproximação dos familiares com o processo educativo. Conclui-se, portanto, que a proposta de aula aberta no modelo de inversão da lógica docente mostrou-se efetivo, pois os familiares participaram e as crianças demonstraram alegria e motivação ao assumirem os seus papeis de professoras.

De nosso ponto de vista, a proposta pedagógica apresentada implica em reflexões para o ensino da temática circense. Em primeiro lugar, contesta uma suposta autoridade do adulto para o ensino, mostrando que todos podem ensinar e aprender. Outro ponto é a necessidade de desconstruir a ideia do estudante passivo ao processo pedagógico, em prol da sua participação ativa no planejamento, condução e avaliação das aulas, haja vista os objetivos de formar estudantes autônomos, capazes de tomar decisões e co-decisões, e comunicativos. 
Por fim, um terceiro aspecto é a pertinência de dialogar com as famílias, apontando o papel da instituição educativa e a riqueza do ensino com a temática circense. Por certo, em um momento em que os papéis sociais atribuídos à escola e à família parecem embaralhados, é fulcral criar espaços de diálogo para reconhecer os limites e as potencialidades de ambas as instituições na educação.

Quanto ao projeto extensionista, o presente trabalho corrobora com outros estudos que apontam a extensão universitária como fértil campo de inovações pedagógicas. O projeto "Atividades circenses para crianças" há mais de dez anos vem comprovando essa tese com uma série de atividades que integram formação docente, ação comunitária e pesquisas científicas. Não obstante aos resultados obtidos, surgiram novas questões que nos convida a prosseguir com a pesquisa: qual a ressonância desta experiência no cotidiano das familias? Qual o impacto desta "aventura pedagógica" na formação dos monitores? Destarte, a emergência de novas perguntas incita-nos a manter a pesquisa na extensão universitária, mas isso ficará para outra sessão.

\section{REFERÊNCIAS}

1. Afonso, J. (2002). Os circos não existem: Família e trabalho no meio circense. Imprensa de Ciências Sociais.

2. Almeida, F. (2017). Educação física escolar e práticas pedagógicas inovadoras: Uma revisão. Revista Corpoconsciência, 21(3), 7-16.

3. Almeida, C., Cagnato, E., \& Dal-lin, A. (2011). Aulas de Educação Física na concepção aberta: Uma experiência no Ensino Fundamental. Em Anais do X Congresso Nacional de Educação - Educare, Curitiba, PR, Brasil.

4. Alonso, V., \& Barlocco, A. (2013). Encastres: propuestas para una escuela en juego - Circo. Coordinación técnica MIDES-CEIP.

5. Andrieu, B. (2016). Aprenda de su cuerpo vivo: una emersiología de los gestos circenses. Revista Latinoamericana de Estudios sobre Cuerpos, Emociones y Sociedad, 8(20), 54-63. 
6. Ariès, P. (2006). Pequena contribuição à História dos jogos e das brincadeiras. Em P. Ariès, História social da criança e da família (2 ${ }^{\underline{a}} \mathrm{ed}$.). Livros Técnicos e Científicos.

7. Benjamin, W. (2009). Reflexões sobre a criança, o brinquedo e a educação ( $2^{\underline{a}}$ ed.). Duas Cidades.

8. Benjamin, W. (2012). Magia e técnica, arte e política: Ensaios sobre a literatura e história da cultura ( $8^{\underline{a}} \mathrm{ed}$.). Brasiliense.

9. Bortoleto, M., \& Celante, A. (2011). O ensino das atividades circenses no curso de Educação Física: Experiências na universidade pública e privada. Em E. Pereira, G. Celani \& D. Grassi (Orgs.), Inovações curriculares: Experiências no ensino superior (pp.178-190). FE/UNICAMP.

10. Bortoleto, M. (2016). Mais arte, mais circo e mais educação: Por um corpo mais expressivo. Em A. Moraes, L. Rocha \& P. Silva (Orgs.), Educação integral no Espírito Santo: Contribuições para as artes do corpo e do espaço (pp.103-115). GM Gráfica \& Ed.

11. Bortoleto, M., Duprat, R., \& Tucunduva, B. (2016). As atividades circenses na FEF-UNICAMP: A construção de uma nova área de estudos e pesquisa. Em M. Bortoleto, T. Ontañón \& E. Silva (Orgs.), Circo: Horizontes educativos (pp.225-257). Autores Associados.

12. Bortoleto, M., Ontañón, T., Duprat, R., \& Tucunduva, B. (2017). O circo na universidade: Por uma coerência entre as práticas de ensino, pesquisas e extensão. Em O. Schneider \& J. Gama (Orgs.), Educação Física e seus caminhos: Programa de Educação Tutorial (pp.139-160). Virtual Livros.

13. Bortoleto, M., \& Silva, E. (2017). Circo: Educando entre as gretas. Rascunhos-Caminhos da Pesquisa em Artes Cênicas, 4(2), 104-117.

14. Bourdieu, P. (2004). Os usos sociais da ciência: Por uma sociologia clínica do campo científico. Editora Unesp.

15. Caramês, A. (2014). Professores na corda bamba: As atividades circenses na formação inicial enquanto conteúdo da educação física [Dissertação de mestrado em Educação Física]. Universidade Federal de Santa Maria, Centro de Educação Física e Desportos.

16. Cardani, L., Spolaor, G., Santos, G., Ontañón, T., \& Bortoleto, M. (2017). Pedagogia das atividades circenses: Quando pais tornam-se aprendizes de seus filhos. Em Anais do XX CONBRACE/ VII CONICEDemocracia e emancipação: Desafios para a Educação Física e a Ciências do Esporte na América Latina. Goiânia, Brasil.

17. Carvalho, M. (2004). Modos de educação, gênero e relações escolafamilia. Cadernos de Pesquisa, 34(121), 41-58.

18. Chioda, R. (2018). Uma aventura da alegria e do risco: Narrativas de um professor de educação física sobre o ensino das atividades circenses [Tese de doutorado]. Universidade Estadual de Campinas, Faculdade de Educação Física. 
19. De Gáspari, J., \& Schwartz, G. (2007). Vivências em arte circense: Motivos de aderência e expectativas. Motriz, 13(3), 158-164.

20. Denzin, N., \& Lincoln, Y. (2005). The Sage handbook of qualitative research ( $3^{\mathrm{a}}$ ed.). Sage Publishing.

21. Desgagné, S. (2007). O conceito de pesquisa colaborativa: A ideia de uma aproximação entre pesquisadores universitários e professores práticos. Revista Educação em Questão, 29(15), 7-35.

22. Duprat, R. (2014). Realidades e particularidades da formação do profissional circense no Brasil: Rumo a uma formação técnica e superior [Tese de doutorado em Educação Física]. Universidade Estadual de Campinas, Faculdade de Educação Física.

23. Faria, B., Bracht, V., Machado, T., Moraes, C., Almeida, U., \& Almeida, F. (2010). Inovação pedagógica na educação física: O que aprender com práticas bem sucedidas? Ágora para la Educación Física y el Deporte, 12(1), 11-28.

24. Fino, C. (2016). Inovação pedagógica e ortodoxia curricular. Revista Tempos e Espaços em Educação, 9, 13-22.

25. Flick, U., Kardorff, E., \& Steinke, I. (2004). A companion to Qualitative Research. Sage Publishing.

26. Freire, P. (2015). Extensão ou comunicação? (17 $7^{\mathfrak{a}}$ ed.). Paz e Terra.

27. Geraldi, J. (2010). A aula como acontecimento. Pedro \& João Editores.

28. Hildebrandt, R., \& Laging, R. (1986). Concepções abertas no ensino da educação física. Livro Técnico.

29. Hildebrandt, R. (2005). Textos pedagógicos sobre o ensino da Educação Física (3aa ed.). Edições Unijuí.

30. Hirai, R., \& Cardoso, C. (2006). Para a compreensão da concepção de "aulas abertas" na Educação Física: Orientada no aluno, no processo, na problematização, na comunicação e... Motrivivência, 27, 119-138.

31. Ibiapina, I. (2016). Reflexões sobre a produção do campo teóricometodológico das pesquisas colaborativas: Gênese e expansão. Em I. Ibiapina, H. Bandeira \& F. Araujo (Orgs.), Pesquisa colaborativa: Multirreferenciais e práticas convergentes (pp.33-62). Editora da Universidade Federal do Piauí - EDUFPI.

32. Krippendorff, K. (2004). Content analysis. An introduction to its methodology ( $2^{\underline{a}}$ ed.). Sage Publishing.

33. Matias, T., Soares, M., Silva, O., Frasson, J., \& Pires, V. (2018). Educação Física escolar no Ensino Médio: O uso das redes sociais nos processos de ensino-aprendizagem a partir da perspectiva de aulas abertas. Pensar a Prática, 21(3), 609-620.

34. Miranda, R., \& Ayoub, E. (2017). Por entre as brechas dos muros da universidade: $\mathrm{O}$ circo como componente curricular na formação inicial em Educação Física. Revista Portuguesa de Educação, 30(2), 61-83. 
35. Miranda, R., \& Bortoleto, M. (2018). O circo na formação inicial em educação física: Um relato auto etnográfico. Revista Brasileira de Ciências do Esporte, 40(1), 39-45.

36. Nóbrega, T. (2008). Corpo, percepção e conhecimento em MerleauPonty. Estudos de Psicologia, 13(2), 141-148.

37. Ontañón, T., Duprat, R., \& Bortoleto, M. (2012). Educação física e atividades circenses: "O estado da arte". Movimento, 18(2), 149-168.

38. Ontañón, T., Santos, G., Spolaor, G., \& Bortoleto, M. (2016). O papel da extensão universitária e sua contribuição para a formação acadêmica sobre as atividades circenses. Pensar a Prática, 19(1), 42-55.

39. Ribeiro, C., Cardani, L., Santos, G., \& Bortoleto, M. (2017). Diálogos circenses: A construção de uma linha de pesquisa na pós-graduação em Educação Física. Em Anais do VII Fórum de Pós Graduação em Ciências do Esporte e IV Fórum de Pesquisadores das Subáreas Sociocultural e Pedagógica da Educação Física. FEF/UNICAMP.

40. Rocha, G. (2010). Circo no Brasil - Estado da arte. Revista Brasileira de Informação Bibliográfica em Ciências Sociais - BIB, 70, 51-70.

41. Rocha, G. (2012). O "circo-escola" e a reinvenção da educação. Em G. Rocha \& S. Tosta (Orgs.), Caminhos da pesquisa: Estudos em linguagem, antropologia e educação (pp.129-154). Curitiba: Editora CRV.

42. Santos, G., Prodócimo, E., \& Ontañón, T. (2016). "Circo Coragem": O jogo como estratégia de ensino das atividades circenses. Nuances: Estudos sobre Educação, 27(1),147-164.

43. Santos, G. (2018). Pedagogia das atividades circenses na Educação Física escolar: Experiências da arte em escolas brasileiras de Ensino Fundamental [Dissertação de mestrado em Educação Física]. Universidade Estadual de Campinas, Faculdade de Educação Física.

44. Silva, E. (1996). O circo: Sua arte e seus saberes: o circo no Brasil do final do século XIX a meados do XX. 162f [Dissertação de mestrado em História]. Universidade Estadual de Campinas, Instituto de Filosofia e Ciências Humanas.

45. Silva, M. (2009). A intencionalidade da consciência em Husserl. Argumentos Revista de Filosofia, 1(1), 45-53.

46. Tonso, S. (2012). A ambientalização da universidade e a extensão universitária. Em P. Leme, A. Pavesi, D. Alba, \& M. González (Orgs.), Visões e experiências ibero-americanas de sustentabilidade nas universidades (pp.65-70). Gráfica Alhambra.

47. Tucunduva, B. (2015). O circo na formação inicial em educação física: Inovações docentes, potencialidades circenses [Tese de doutorado]. Universidade Estadual de Campinas, Faculdade de Educação Física.

48. Yin, R. (2001). Estudo de caso: Planejamento e métodos (2 $2^{\underline{a}}$ ed.). Bookman. 